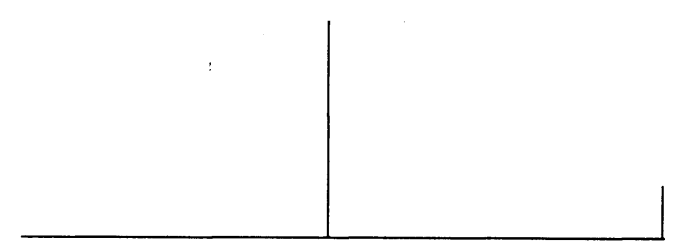

\title{
Autismo e defesa primária: questões sobre o sujeito e a transferência
}

Lou Muniz Atem

Este artigo pretende discutir a clínica do autismo a partir de aspectos referentes à transferência e ao surgimento do sujeito.

$O$ autismo, momento da constituição anterior à formação da "imagem corporal" $e$ do "eu", é um momento onde não podemos ver um sujeito constituído. A falta de olhar, de linguagem, o isolamento ativo, a recusa ao outro, nos fazem ver uma criança para quem as instâncias da consciência e do inconsciente não estão ainda instituídas.

$\mathrm{Na}$ transferência pode ocorrer um desinvestimento por parte do analista, o que fará obstáculo à continuação do tratamento. É preciso que o analista possa permitir a continuidade do circuito pulsional, supondo sempre um sujeito, mesmo onde ele parece não querer existir ou se fazer mostrar. Disto, resulta a possibilidade de todo tratamento do autismo. 


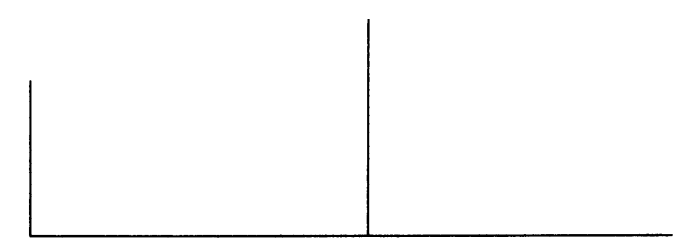

$\mathrm{Na}$ sala de atendimento, meus braços seguravam Mateus enquanto andávamos na escuridão. Apenas a luz de uma lanterna grudada em seu rosto era visível. Meus olhos se abriam com força na tentativa de enxergar algo. Com algum esforço continuo segurando-o e guiando-o. Meus braços começam a doer e eu o solto. Ele cai como um bloco sobre o chão, como se não tivesse forças para segurar o peso do próprio corpo. Ao cair, seu corpo permanece duro, estático e apenas a lanterna, em seus olhos, parece existir para ele. Tento olhá-lo, mas o olho que não está na lanterna, vesgo, procura a luz que o mantém vivo. Chamo-o pelo nome, toco seu braço, mas nada parece substituir esse instante congelado entre seu corpo e o breve facho luminoso. Mateus, que não ouve e não vê, parece não se importar com nada, desde que a luz não lhe seja roubada.

No $1^{2}$ Congresso Brasileiro de Psicopatologia Fundamental (abril/96), em debate a respeito do autismo, surgiu a pergunta: "o autista sofre?". Em termos conceituais, a palavra sofrimento está ligada à consciência, não podendo, portanto, ser referida ao autista, mas, com base na clínica, assim como o paradoxo do autismo, permanecia 


\section{ARTIGOS}

para mim o paradoxo da angústia: esta questão permanece e manifesta-se na forma do pânico frente à aproximação de alguém, do fechamento autístico quando da retirada de um objeto que visa reforçar as defesas e isolamento. Paradoxalmente também, o que me angustiava naquela criança parecia ser justamente o que a tranqüilizava: o isolamento do mundo era sua fortaleza e proteção, o chão e a luz de uma lanterna seu refúgio. Neste texto usarei, então, a palavra angústia como correlato de uma experiência de ameaça psíquica (o pânico e fechamento autísticos), onde o "sujeito" se vê na condição de defender-se de um suposto invasor externo.

Em se tratando do autismo, qualquer questão que se coloque em relação à angústia, pânico ou recusa ao outro, é preciso anexar a questão referente à existência ou não do "sujeito". Tido como um momento anterior ao da construção da imagem corporal, e anterior à ligação do bebê com o mundo, o autismo seria, por isso, um momento onde o sujeito ainda não se constituiu, "eu" e "inconsciente" são instâncias das quais ainda não se pode falar. Por isso os profissionais, psicanalistas ou não, se perguntam se a criança autista estaria mais próxima da natureza do que da cultura, mais próxima do animal do que do humano... Que outra pergunta poderia parecer mais propícia quando nos deparamos com uma constante recusa ao olhar, ao contato, à linguagem e à proximidade de alguém?

Ao trabalhar com Mateus, vi-me colocada diante desta recusa de tal forma, que mal podia formular a pergunta com relação ao sujeito de maneira coesa, tal era a força que sentia a repelir-me, afastar-me, manter-me à distância. Dito de outro modo, conseguia apenas me perguntar se aquela criança sofria, posto que a cada encontro, eu era tomada pela indagação e angústia frente, sua inércia e isolamento. Foi então, a partir da angústia produzida em mim pelo seu mecanismo de afastamento e recusa ao mundo que comecei a pensar esta clínica.

A constituição do sujeito passa necessariamente pelos tempos da alienação e separação, tempos em que o corpo (enquanto efeito do olhar materno) e o eu se constroem. Ora, é justamente o olhar o primeiro a chamar a atenção nestas crianças, pois não há como não ser atingido pelo seu desvio ao apelarmos para um cumprimento, uma palavra, um contato. Outro fator que nos chama a atenção é exatamente a força do desvio deste olhar. Há neste desvio tanto intensidade quanto intenção, os quais são contraditórios à passividade que comumente associamos a estas crianças. Mateus, criança de 8 anos com seqüelas auditivas e visuais de rubéola congênita, que a tudo recusava e de tudo desviava, possuía no entanto uma fonte, possivelmente de onde retirava sua força e intenção de vida: a luz, que despejava em seus olhos aquilo que a outros não era permitido.

$\mathrm{O}$ tratamento com Mateus durou 8 meses, ao longo dos quais tentei injetarlhe tanto vida quanto energia para ligar-se ao mundo. Mas, a cada dia, me via ir 


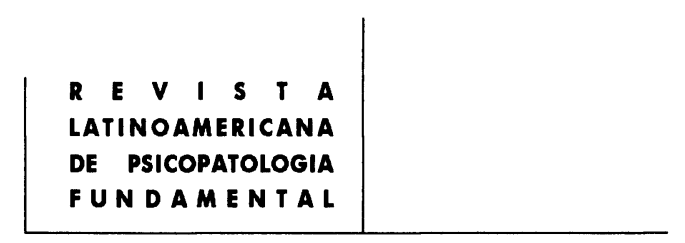

perdendo as forças, andava com ele pela escuridão sustentando seu corpo que pesava sempre mais, e cada sessão se assemelhava a uma dura caminhada pelo deserto. Sem poder investir nesta criança, decidi parar o tratamento e, desde então, me pus a pensar sobre os efeitos e significados desta clínica, onde não há um sujeito constituído e em relação. Outro paradoxo, pois olhando com os olhos destas crianças, somos nós, na realidade, quem não existe e não está constituído, e é preciso partir deste ponto de vista para poder compreendê-las.

Para isto, penso ser extremamente útil o que dizia acima sobre a intenção e atividade em jogo no afastamento e recusa que elas realizam do mundo. Laznik ${ }^{\prime}$ retoma Lacan e chama este afastamento de elisão - mecanismo de defesa próprio ao sistema perceptivo, onde, por haver uma retirada maciça de investimento do mundo, a percepção de um objeto pode subitamente cessar, como se o objeto não existisse e nunca tivesse sido inscrito para a criança.

Estar no mundo, através do isolamento ativo, é de certa forma portar um desejo. Tal foi a questão que me trouxe Mateus: por que há algo de particular em jogo, algo que porta uma intenção e intensidade (no caso o interesse pela luz), podemos falar em sujeito? Tal é também o paradoxo que o autista constantemente nos traz: a surpresa diante daquilo onde não se pensava nada existir. Mateus, o menino das cavernas, que vivia no escuro, enxergando através de um pequeno facho luminoso, parecia não querer viver/existir. No entanto, agarrava-se à luz como se agarra um último fio de vida, onde podia então existir, para além do mundo e da percepção, e a despeito de todos nós.

A pergunta sobre quem é o sujeito autista há algum tempo intriga os analistas. Seguindo a pista de Mateus, é um sujeito preso entre a não existência da escuridão e uma pequena brecha de ar que só pode chegar até ele na condição de que nada mais em volta o toque. Esta é sua exigência de vida: que nada o alcance, nada o perturbe, e, para isso, é preciso enxergar, ouvir e sentir apenas o mínimo daquilo que está em volta.

Podemos falar em defesa no caso dos autistas, se falarmos em defesa primária, onde o organismo tende completamente à homeostase, não suportando o menor grau de desprazer. Esta forma de defesa ${ }^{2}$ (elisão) tem como meta isolar e proteger o organismo de qualquer percepção dolorosa, regulando a quantidade de excitação que lhe é enviada (sempre tendendo a que esta última se iguale a zero). Tal defesa, quando levada a extremos (como no caso do autismo), pode separar completamente o organismo do mundo, gerando um evitamento generalizado de

1. M.-C. Laznik-Penot. Rumo à palavra. Três crianças autistas em psicanálise. São Paulo, Escuta, 1997.

2. M.-C. Laznik-Penot. "Défenses autistiques et échec de la mise en place de la fonction de représentation". La Psychanalyse de l'enfant, 1996, n² 19. 


\section{ARTIGOS}

qualquer representação que possa suscitar desprazer (vale dizer que apenas a aproximação de alguém passa a representar ameaça). A defesa primária investe assim o pólo perceptivo, porém, numa meta defensiva, onde reconhece os elementos que vêm do outro, mas para evitar seus traços principais: seu olhar e sua voz. Justamente os traços mais marcantes do investimento que a mãe faz sobre o bebê, levando a que o sujeito se constitua, por vias tão distintas do corpo biológico.

Para que esse investimento seja eficaz, é preciso que o bebê possa recebêlo, assim como é preciso que experiências de satisfação sejam repetidas ${ }^{3}$, e possam fazer um caminho até se tornarem representação. Se tais experiências não são suficientemente satisfatórias ou não se repetem o bastante, passará a haver, por parte do bebê, um evitamento dos estímulos que lhe chegam, já que passam a ser tidos como da ordem do desprazer. Este evitamento (defesa primária) é o que cortará o caminho para que se dê a construção da ligação pulsional do bebê com o outro.

Voltando à pergunta colocada acima, se tal evitamento ativo, pela intenção que comporta, pode nos levar a pensar em um sujeito autista, é preciso lembrar que o sujeito está sempre referido ao inconsciente, ao passo que o assumir uma posição ativa (mesmo que para recusar o outro) refere-se à ação, à vontade e, portanto, estaria referido à consciência (ainda que esta não esteja formada para o autista). Voltamos então ao início, onde pensávamos que não existe sujeito no autista e que este está afastado por completo do humano e da cultura?

Laznik ${ }^{4}$, seguindo Freud em "Pulsões e seus destinos" (1915), afirma que o sujeito surge quando pode se completar o circuito pulsional, ao longo do qual o pequeno ser passa por três fases em relação ao objeto: a fase ativa, a reflexiva (onde a pulsão volta-se sobre ele mesmo) e a passiva. É só no terceiro tempo, o da passividade, quando há uma sujeição aos cuidados e ao desejo do Outro/outro, que o sujeito pode surgir (tempo da alienação). Algo coerente, já que o inconsciente, assim como o eu, não nasce com o bebê, mas é construído a partir de sua relação com o mundo.

Incomodava-me olhar para Mateus, pois identificava para mim uma posição da ordem do impossível: o travar contato com quem parecia não querer partilhar comigo um pouco da luz que o preenchia, deixando-me, assim, na escuridão. Tal transferência, que nos coloca muitas vezes num lugar de impotência e paralisia, é talvez a pedra molar de todo tratamento de autistas. Assim como em tratamento de neuróticos, é preciso escapar àquilo que nos está reservado, e supor a

3. Idem, p. 18 .

4. M.-C. Laznik-Penot. "Do fracasso da instauração da imagem do corpo ao fracasso da instauração do circuito pulsional. Quando a alienação faz falta", in M.-C. Laznik-Penot (org.) O que a clínica do autismo pode ensinar aos psicanalistas. Salvador, Ágalma, 1991. 


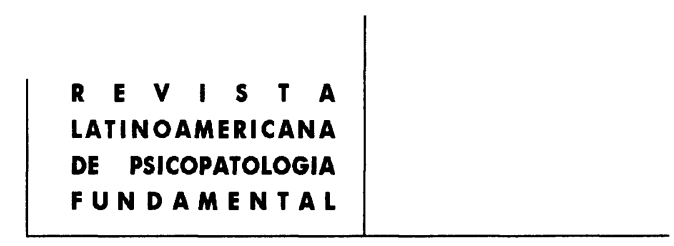

possibilidade da mudança onde ela não quer se mostrar, supor um sujeito onde ele parece afirmar não existir.

O autismo, para Laznik (1991), coloca em evidência uma falha fundamental na presença do Outro (papel ocupado de início pela mãe), o que se traduziria por uma falha na possibilidade que o olhar tem de trazer consigo o investimento libidinal necessário para a construção imaginária do corpo e do eu. É o olhar, quando traduz a presença, que permite à criança receber/ouvir a voz da mãe (também enquanto signo de investimento). Esta hipótese possibilita pensarmos que quando a relação especular não se instaura (pelo olhar), também não é possível à criança ouvir sua mãe, o que significa não ouvir aquilo que as palavras dizem do lugar reservado a esta criança, do desejo que lhe é depositado. Isto nos possibilitaria pensar a surdez dos autistas enquanto surdez subjetiva, onde, quando o investimento e a presença do Outro não são possíveis, também não é possível escutar, o que vemos demonstrado em muitas crianças autistas dadas como surdas, sem que haja, no entanto, qualquer lesão orgânica que o justifique.

É pelo mecanismo de defesa do evitamento, que vimos acima, que isto se torna possível, uma vez que tal mecanismo se trata de um completo desinvestimento da capacidade de percepção, principalmente da audição e da voz.

Tiago, garoto de 6 anos, com seqüela de rubéola, foi tido como surdo e lhe foi indicado o uso de aparelho auditivo. Participa de tratamento em grupo (do qual sou estagiária) e individual na Pré-Escola-Terapêutica Lugar de Vida. Os exames, inconclusivos, não puderam especificar o grau de sua deficiência, embora os profissionais que trabalham com ele (psicanalistas, foniatra, fonoaudióloga) concordem em que sua surdez não seja profunda e não justifique a ausência de linguagem.

Após algum tempo do uso do aparelho, Tiago retornou ao hospital que o atendia para refazer os exames. Mais uma vez não foi possível concluí-los integralmente, mas, um dos exames, feito com a criança sedada e, portanto, não precisando de sua colaboração para o resultado, indicou surdez profunda no ouvido esquerdo (quanto ao direito não foi possível verificar, tendo a criança acordado). As dúvidas, no entanto, continuam, pois percebemos que muitas são as reações de Tiago a situações de barulho e, mesmo, ao nosso chamado. De fato, há relatos de tratamentos com estas crianças em que os resultados de exames alteram de uma época para outra, de maneira a deixar dúvida se há ali realmente uma deficiência.

5. Idem, p. $38 n$. 


\section{ARTIGOS}

Laznik $^{6}$ relata o caso de Maxime, criança de dois anos e meio, cujos médicos referem danos cerebrais em relação à visão e audição (com perda de $30 \%$ e $40 \%$ em cada um dos ouvidos). Assim como para Tiago, pensava-se que esta falha auditiva não explicava a ausência de linguagem. Um ano após começar o tratamento analítico, o audiograma revelou uma audição normal. A hipótese da autora é de que há para os autistas traços mnésicos que foram investidos no início da vida, porém falha o "caminho" que pode levar a estes traços para que eles sejam acessados, tornados representação e possibilitem toda a riqueza e flexibilidade do pensamento inconsciente. Pouco importa aqui, se a falha no circuito (no caminho) se deu por uma dificuldade do bebê ou por uma dificuldade do Outro em responder ao bebể. O importante é que o tratamento analítico possibilite, pela circulação pulsional, que estes caminhos possam ser retomados e reinvestidos.

Tiago, diferentemente da criança citada pela autora, não entrou em tratamento (apenas em termos de exames orgânicos) assim que traços autísticos foram percebidos. Podemos imaginar que até a idade de seis anos esta criança tenha encontrado maneiras de prolongar e reforçar suas defesas e seu evitamento do mundo.

Tiago produz diversas vocalizações, sons em diversos tons e intensidades. Anda em círculo pela sala, girando os braços ao redor do corpo e "falando", como se estivesse a nos contar histórias. Com relação à audição, há outras dúvidas: fica completamente impassível diante de um barulho forte e incômodo, mas vira-se para olhar quando algo pequeno cai no chão. Indagar se isto se deve à própria falha auditiva ou a um desinvestimento do pólo auditivo, far-nos-ia retornar às peculiaridades do evitamento generalizado realizado pelo autista; uma vez que, além da audição, há o evitamento do olhar, a inexpressividade facial, as estereotipias gestuais, sendo que estes últimos não se devem a qualquer falha auditiva ou orgânica. No entanto, os próprios dados clínicos nos mostram que o evitamento autístico pode ter momentos de lapsos e falhas, quando a criança é atingida por estímulos externos e entrega-se a momentos de participação e interesse. Porém, quando isto ocorre, há normalmente uma volta ao fechamento.

Assim, apesar de ter sido trazido tardiamente, começamos a perceber em Tiago alguns efeitos do tratamento. Aumentam relatos (inclusive maternos) que indicam que a criança começa a atender a alguns chamados ou pedidos que lhe são dirigidos. Vemos uma criança que, a despeito de sua distância e isolamento,

6. M.-C. Laznik-Penot. "Défenses autistiques et échec de la mise en place de la fonction de représentation". La Psychanalyse de l'enfant, 1996, n 19, pp. 5 e 6.

7. M.-C. Laznik-Penot. "Pourrait-on penser à une prévention du syndrome autistique?", p. 11. 


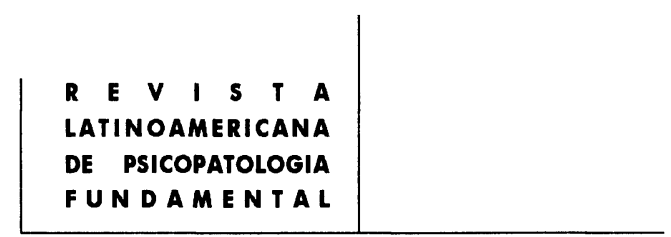

é capaz de abraçar e deitar-se no colo de alguém, uma criança que, mesmo não conseguindo se aproximar, demonstra interesse por jogos e brincadeiras realizados pelos outros.

No trabalho em grupo, Tiago passa a demonstrar interesse em olhar sua imagem no espelho, começa a nos olhar nos olhos, buscar partes do corpo de outra criança (calçando suas meias e tênis). A qualidade de seu desenho muda e em vez de rabiscos sem controle, aparecem pequenos círculos que se assemelham a letras enfeitadas por uma borda colorida.

Freud" chama a nossa atenção para aquilo que ele toma como "ambivalência da pulsão" e que consiste no fato de a passagem pelas três fases do circuito pulsional não implicar nunca toda a quota pulsional, levando a que a pulsão não se transforme por inteiro. A direção ativa, por exemplo, estará sempre "convivendo" com o seu oposto passivo ou reflexivo e assim para qualquer modalidade de pulsão. Tal ambivalência, para Freud, é própria à pulsão e ao humano.

É, então, pela maleabilidade característica às pulsões que se pode pensar na possibilidade de fazer surgir um sujeito no autista, já que a pulsão, por não possuir um destino ou modalidade única, pode, em determinado momento, voltarse ao mundo, gerando uma forma de ligação não antes conhecida. Sobre tal hipótese está ancorada toda possibilidade de tratamento com autistas. No âmbito do tratamento, é necessário que o analista possa sempre ver um sujeito, mesmo onde ele não quer existir, pois daí resulta o possível do tratamento do autismo.

No relato destes dois casos, percebemos duas saídas muito distintas quanto à continuidade do tratamento (lembrando que tive que decidir parar o tratamento com Mateus). Podemos fazer um paralelo onde ao desinvestimento da criança em relação ao mundo corresponderia, em alguns casos mais graves de autismo, um momento da transferência em que ocorre um desinvestimento global por parte do analista, o qual pode fazer obstáculo à própria continuidade do tratamento? A falta de resposta de uma criança, seja em termos de fala, de brincar, de olhar ou de qualquer forma de contato, pode levar a que o isolamento se dê dos dois lados, e a que o circuito pulsional não se complete com quem quer que se aproxime deste pequeno ser?

Se assim for, a transferência e repetição próprios à situação analítica ocorrem com crianças autistas como em todo tratamento. É tendo em vista esta transferência, que podemos chamar de "isolante, que repele", que passo, a partir do tratamento com Mateus, a pensar esta clínica. Seria possível dizer que a questão coloca-se de modo inversamente proporcional: quanto menos sujeito há

8. S. Freud. "Os instintos e suas vicissitudes" in Obras Completas, vol. XIV. Rio de Janeiro, Imago, 1977. 


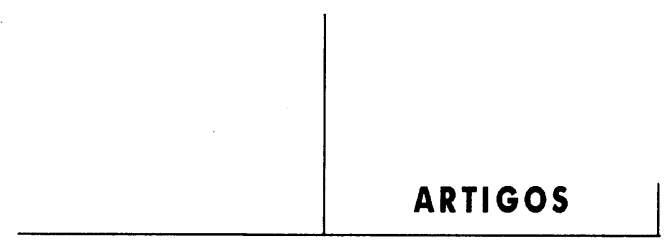

na criança, maior o investimento necessário do analista para que o trabalho possa se dar, ainda que a principal questão colocada de início seja a do desinvestimento. Paralelo ao trabalho com a criança, um outro trabalho deve ocorrer. Este, com o analista, no caso do tratamento com autistas; no sentido de que ele não se "defenda primariamente" da recusa que lhe é enviada, para poder continuar a investir em pequenos (mas significativos) movimentos e ruídos que venham da criança.

\section{Resumos}

La intención de este trabajo es discutir la clinica del autismo a partir de aspectos que se refieren a la transferencia y al surgimiento del sujeto.

El autismo - momento de la constitución anterior a la formación de la "imagen corporal" y del "yo" - es un momento en el cual no podemos ver un sujeto constituido. La falta de mirada, la ausencia de lenguaje, el isolamiento activo y la recusa del otro nos revelan un niño para quien las instancias de la consciencia y del inconsciente no están aún constituidas.

Puede ocurrir que en la transferencia exista una falta de envolvimiento por parte del analista creando un obstáculo para la continuación del tratamiento. Es necesario que el analista pueda permitir la continuidad del circuito pulsional suponiendo siempre un sujeto, aunque éste parezca no querer existir o poder mostrarse. La posibilidad del tratamiento del autismo depende de ésto.

The purpose of this article is to discuss clinical practice with autism dealing with aspects which refer to transference and the emergence of an individual.

Autism - moment in the constitution of humans prior to the composition of "body image" or "self" - is a moment at which we can not observe a constituted self. The lack of countenance, the absence of language, the active isolation and the refusal to recognize another reveal a child for whom the instances of conscience and unconscious are not yet established.

It is possible for the analyst not to invest sufficiently in the transferencial relationship thus creating an obstacle for the continuation of the treatment. It is essential that the analyst permit the continuation of the energetic circuit always presupposing the existence of a self, even if it seems not to exist or is not able to manifest itself. Treating autism clinically depends on this. 